\title{
Covid 19 Sürecinde Sınırlı Bağımsız Denetim ve BIST 100 Şirketleri Üzerine Bir Araştırma
}

\author{
Mehtap Karakoç* - Meral Gündüz ** \\ * Dr. Öğr. Üyesi Uşak Üniversitesi/Uygulamalı Bilimler Fakültesi Uşak/Türkiye \\ E-Posta: mehtap.karakoc@usak.edu.tr ORCID: 0000-0003-0349-4571 \\ ** Dr. Öğr. Üyesi Uşak Üniversitesi/Uygulamalı Bilimler Fakültesi Uşak/Türkiye \\ E-Posta: meral.gunduz@usak.edu.tr \\ ORCID: $\underline{0000-0002-9255-091 X}$
}

\section{Öz}

2019 yılı Aralık ayı itibariyle Koronavirüsün tüm dünyada yayılmasıyla birlikte dünya genelinde çeşitli kısıtlamalar getirilmiştir. Bu kısıtlamalar şirketlerin finansal tabloların ve denetim çalışmaların da etkilemiştir. Bu çalışmada Covid-19 döneminde Borsa İstanbul 100 endeksinde yer alan şirketlerin ara dönem finansal tabloları ve sinırl denetim raporları incelenmiştir. Bu çalışmanın amacı, Covid-19'un bă̆grmsız denetim sürecine etkilerinin incelenmesi ve sınırl denetim raporlarında Covid-19 etkilerine ne ölçüde yer verdiklerinin saptanmasıdır. Çalışmanın sonucunda 99 şirketin finansal tablolarında Covid-19'un etkilerine yer verdikleri tespit edilmiştir. Ayrica sadece 5 şirketin sinırl denetim raporlarında Covid-19'un etkilerine ait ifadelere yer verdikleri görülmüş̧ür. Sınırlı denetim raporunda Covid-19'un etkilerine yer veren şirketlerin büyük çoğunluğunun bu etkilere "Dikkat Çekilen Husus" başlı̆̆ı altında yer verdikleri tespit edilmiştir. Covid-19 etkisine sinırlı denetim raporlarında yer veren beş şirketin raporlarmda, denetim strasında Covid-19 nedeniyle uzaktan denetim tekniklerinden yararlanıp yararlanmadıklarına iliş̧kin herhangi bir ek ifadeye yer verilmemiştir. Yine bu raporlarda şirketlerin pandemi nedeniyle ek denetim tekniklerine başひurduklarına dair de bir açıklamaya rastlanmamıştır.

Anahtar Kelimeler: Bağımsız Denetim, Sınırlı Bağımsız Denetim, Sinırlı Bağımsız Denetim Standartlarl, Covid-19, BIST 100 


\title{
Review of Financial Statement in the Covid-19 Process and a Research on BIST-100 Companies Article
}

\begin{abstract}
By the year 2020 of December, with the spread of the coronavirus worldwide, various restrictions have been imposed. These restrictions have also affected the financial statements and audit work of the companies. In this study, interim financial statements and limited audit reports of companies included in the BIST-100 during the Covid-19 period were examined. The aim of this study is to investigate to what extent the companies included in BIST-100 include the effects of COVID-19 in their interim financial statements and limited audit reports. As a result of the study, it was determined that 99 companies included the effects of Covid-19 in their financial statements. In addition, it was seen that only 5 companies included statements about the effects of Covid-19 in the limited audit reports. It was determined that most of the companies that included the effects of Covid-19 in the limited audit report showed these effects under the same heading "Attention Aware". In the reports of the five companies that included the Covid-19 effect in their review of financial statements, no additional statements were made regarding whether they benefited from remote control techniques due to Covid-19 during the audit. Further, in these reports, there is no explanation that companies used additional audit tools due to the pandemic.
\end{abstract}

Keywords: Independent Auditing, Review of Financial Statement, International Standard on Review Engagements, Covid-19, BIST 100 


\section{Giriş}

Çin'den dünyanın birçok ülkesine yayılan Koronavirüs'ün dünya genelinde yayılmasıyla Dünya Sağlık Örgütü (World Health Organisation-WHO) tarafından 11 Mart 2020 tarihinde pandemi ilan edilmiştir. Yeni tip koronavirüsü (Covid-19) ile birlikte birçok ülkede sosyal ve ekonomik hayatla ilgili kısıtlamalar uygulamaya geçirilmiştir. Bu kıstllamalar şirketler üzerinde önemli ekonomik etkilere neden olmuş ve bu olumsuz etkiler devam etmektedir. Şirketlerin muhasebe sistemleri, finansal raporları ve denetimleri de bu olumsuzluklardan etkilenmiştir.

Türkiye'de Türkiye Serbest Muhasebeci Mali Müşavirler ve Yeminli Mali Müşavirler Odaları Birliği (TÜRMOB) finansal tabloların denetimi için denetçilere uygulama önerileri yayınlamıştır. Bu önerilerde şirketlerin ve denetçilerin hesapların hazırlanması ve denetim faaliyetlerinin uygulanmasında bazı güçlüklerle karşılaşabilecekleri ve seyahat, toplantılar ve şirketlerin sitelerine erişimde karşılaşılan kısıtlamalar nedeniyle uyguladıkları prosedürleri geliştirmeleri gerektiği belirtilmiştir. Ayrıca grup denetim incelemelerinde, grup denetçilerinin görevlerini yerine getirmek için topluluğa bağ $\iota_{\curlywedge}$ birim denetçilerinin çalışmalarını incelemek için yapacakları değerlendirmeyi ne şekilde planladıklarını göz önünde bulundurmalıdırlar. Örneğin, seyahatin k1sttlarının olduğu yerlerde kullanılacak alternatif denetim prosedürlerine ihtiyaç olup olmadığı dikkate alınmalıdır (TÜRMOB, 2020, s. 12-13).

Ayrıca Kamu Gözetimi, Muhasebe ve Denetim Standartları Kurumu (KGK) da "COVID-19 Salgınının Yürütülen Bağımsız Denetimlere Etkisi" başlıklı bir açıklama yayınlamıştır. Covid-19 döneminde seyahat ve şirket ziyaretlerine dair kisttlamalardan dolayı denetçilerin denetim kanitlarının planlanan nitelikte ve zamanda elde edememesi durumlarında yeterli ve uygun denetim kanıtı toplamak için alternatif yöntemleri değerlendirmeleri gerektiğini ifade etmiştir. Denetçinin daha fazla teknoloji destekli prosedürleri kullanması alternatif yöntemler olarak gösterilmiştir. Ancak bu durumda toplanan kanıtların yeterli ve uygun nitelikte olmasının belirtilmesi ve belgelendirilmesi şarttır. Bu belgelendirme işleminde bu tür kanıtların kalitesinin ve güvenilirlik riskinin daha düşük olabileceğinin ve denetçinin bunu ne şekilde ele aldığını da belirtilmesi gerekir. Bu açıklamaya göre denetçinin, fiziksel incelemenin hangi kalemlerin test edilmesinde önemli olduğu ve ne şekilde yürütülmesi gerektiğinin gözden geçirilmesinin vazgeçilmez olduğu 
ifade edilmiştir. Ayrıca denetçinin alacağı çeşitli kararların ve bazı denetim prosedürlerinin zamanlamasının önemli bir etkiye sahip olup olmadığını ve önemli prosedürlerin getirilen kısıtlamalar nedeniyle zamanında yerine getirilmemesinin denetçinin görüşü üzerindeki etkilerinin değerlendirmesi gerekebileceği belirtilmiştir (www.kgk.gov.tr).

Bu çalışmada sınırlı bağımsız denetim hakkında teorik bilgi verilmiş ve Borsa İstanbul 100 endeksinde (BİST-100) yer alan şirketlerin 1 Ocak- 30 Haziran 2020 ara hesap dönemine ait finansal tabloları ve sinırlı denetim raporları incelenmiştir. BİST-100 şirketlerinin Covid-19'dan ne ölçüde etkilendikleri ve ara döneme ait finansal tablolarında ve sınırl denetim raporlarında bu etkilere ne ölçüde yer verdikleri araştırılmıştır. Çalışma sınırlı denetime ilişkin literatürde benzer bir çalışma yapılmamış olması açısından önemlidir. Ayrıca yıllık finansal tablolar ve bağımsız denetim raporunda yapılacak yeni çalışmalara da ışık tutacaktır.

\section{Sınırlı Bağımsız Denetim}

Türkiye'de KGK tarafından yayımlanan Türkiye Denetim Standartları, Uluslararası Muhasebeciler Federasyonu (International Federation of Accountants-IFAC) tarafindan yayımlanan standartları baz almaktadır. 6102 sayılı Türk Ticaret Kanunu'nun kabulüyle 2012 yılında yayımlanan Bağımsız Denetim Yönetmeliği Türkiye Denetim Standartlarını, bağımsız denetim konusunda uluslararası standartlarla uyumlu eğitim, etik, kalite kontrol ve denetim standartları ile bu alandaki diğer düzenlemeler olarak açıklamaktadır (KGK, 2019, s. 1).

1978 yılında Uluslararası Muhasebeciler Federasyonu (International Federation of Accountants-IFAC) çatısında kurulan Uluslararası Denetim ve Güvence Standartları Komitesi (International Auditing and Assurance Standards Committee- IAASC) 2002 yılında Uluslararası Denetim ve Güvence Standartları Kuruluna (International Auditing and Assurance Standards Board- IAASB) dönüşmüştür (Uyar, 2015: 18). IFAC'ın bünyesinde yer alarak eğitim, etik, kalite kontrol ile güvence denetimi ve ilgili hizmetler standartlarını yayımlayan üç kuruldan biri olan bu Kurulun görevi bağımsız denetim, sınırlı bağımsız denetim, diğer güvence hizmetleri ve ilgili hizmetlere dair standartları yayımlamaktır (KGK, 2019, s. 1). 
Uluslararası Denetim ve Güvence Standartları Kurulu tarafindan yayımlanan bu standartların 100-999 arasında yer alan standartlar, tarihi finansal bilgilerin bağımsız denetiminde uygulanan Uluslararası Bağımsız Denetim Standartları (International Standards on Auditing-ISA)'dır. 3000-3699 arasında yer alan standartlar ise tarihi finansal bilgilerin bağımsız denetimi ve sınırlı bağımsız denetimi dışında kalan güvence denetimlerinde uygulanan Uluslararası Güvence Denetimi Standartları (International Standard on Assurance Engagements- ISAE)'dır. Uluslararası İgili Hizmetler Standartları (International Standard on Related Services- ISRS) ise 4000-4699 arasinda kalan standartlar olup, Kurulun güvence denetimleri dışında kalan ilgili hizmetlere dair yayımladığı standartlardır.

Uluslararası Denetim ve Güvence Standartları Kurulun yayınladığı standartlardan 2000-2699 arasında kalan standartlar Uluslararası Sınırlı Bağımsız Denetim Standartları (Engagements to Review Financial Statements- ISRE) olarak adlandırılmaktadır. Bu standartlar ara dönem finansal raporlar da dahil olmak üzere tarihi finansal bilgilerin "sınırlı bağımsız denetimlerinde" uygulanmaktadır.

KGK tarafından Sınırlı Bağımsız Denetim alanında yayımlanan iki standart bulunmaktadır. Bunlardan ilki Sınırlı Bağımsız Denetim Standardının (SBDS) "2400 Tarihi Finansal Tabloların Sınırlı Bağımsız Denetimi” standardıdır. Diğeri ise Sınırlı Bağımsız Denetim Standardının (SBDS) “2410 Ara Dönem Finansal Bilgilerin, İşletmenin Yıllık Finansal Tablolarının Bağımsız Denetimini Yürüten Denetçi Tarafından Sınırlı Bağımsız Denetimi" standard1dir.

KGK sınırlı bağımsız denetimi, kullanıcılarına tarihi finansal bilgilerin güvenilirliği bakımından sınırlı seviyede bir güvence sağlayan denetim türü olarak tanımlamaktadır (KGK, 2019: s. 2). SPK ise sınırlı bağımsız denetimi, finansal tabloların Kurulun yayımladığı finansal raporlama standartlarına uyumu konusunda öncelikle soruşturma yapılarak ve analitik inceleme teknikleri yardımılla incelenmek suretiyle "finansal tablolarla ilgili önemli yanlışlıkların bulunmadığını"” raporlanması şeklinde ifade etmektedir. Böylece işletmelerin ara dönemlerine ait finansal raporlarının incelenmesi sağlanmış olmaktadır (SPK Seri X, No: 22, 34. Kısım ).

SPK sınırlı bağımsız denetime tabi şirketleri; "yatırım kuruluşları, yatırım fonları hariç kolektif yatırım kuruluşları, ipotek finansmanı kuruluşları ve 
sermaye piyasası araçları bir borsada ve/veya teşkilatlanmış diğer pazar yerlerinde işlem gören anonim ortaklıklar" olarak açıklamıştır (SPK Seri X, No: 22, md 5).

Ara dönem finansal raporlamaya ilişkin denetimden sorumlu denetçi, yapacağ sınırlı denetimi “SBDS 2410 Ara Dönem Finansal Bilgilerin, İşletmenin Yıllık Finansal Tablolarının Bağımsız Denetimini Yürüten Denetçi Tarafından Sınırlı Bağımsız Denetimi"' standardına uygun gerçekleştirmelidir. Bu standartta sınırlı denetimin amacl; denetçinin işletmenin ara döneme ait verilerinin finansal raporlama çerçevesine uyumu hususunda bir sonuç bildirmesi olarak açıklanmıştır. Eğer denetçi önemli bir yanlışlığın varlığının kanaatine varırsa uygun olmayan bir sonuç bildirme riskini orta düzeye çekmek için sorgulamalar yaparak, analitik prosedürler ile diğer sınırlı denetim prosedürlerini uygulayabilmektedir (SBDS 2410, prg. 7). Ayrıca aynı standart denetçi tanımını yaparken, işletmenin yıllık denetimlerinin yanında ara döneme ilişkin finansal bilgilerinin sınırlı denetimini yürüten kişi şeklinde ifade etmiştir (SBDS 2410, prg. 1).

Ara dönem finansal bilgilerin sınırlı denetiminin amacı bağımsız denetim standartlarına göre uygulanan denetim amacından farklılık göstermektedir. Ara dönem finansal bilgilerin sınırlı denetimi finansal bilgilerin tüm boyutlariyla gerçeğe uygun sunumu konusunda bir sonuç bildirmesine imkan sağlamamaktadır (SBDS 2410, prg. 8).

Bir sınırlı denetim, finans ve muhasebe sorumluları öncelikli olmakla beraber tüm ilgililerin sorgulanması ile analitik prosedürlerin ve diğer sınırlı denetim prosedürlerinin uygulanmasından oluşmaktadır. Sınırlı denetim, bağımsız denetimin gerektirdiği tüm kanıtları sağlayamamakta, sadece ara dönem finansal bilgileri etkileyen önemli hususları denetçinin dikkatine sunmaktadır (SBDS 2410, prg. 9). Dolayısıyla sınırlı bağımsız denetim sürekli bağımsız denetime göre ikinci derecede güvence sağlamaktadır (Uyar, 2015: s. 20). Ayrıca sınırlı denetim sırasında denetçinin vardığı sonucu etkilemeksizin, işletmenin sürekliliğinin tehlikeye düşmesi ile ilgili bir olay ya da şartla ilgili önemli belirsizliğe vurgu yapmak amacıyla denetçi rapora "Dikkat Çekilen Hususlar" paragrafı ekleyebilir. Denetçiler ara dönemde yayınlanan raporlarda işletmenin sürekliliğini tehlikeye sokacak bir belirsizliğin yeterli düzeyde açıklanmadığı kanaatine varırlarsa, şartlı veya olumsuz sonuç bildirerek raporda bu duruma özel olarak yer verebilirler (SBDS 2410, prg.56-59). 


\section{Sınırlı Bağımsız Uzaktan Denetim Ve Kullanılan Prosedürler}

COVID-19'un Türkiye' de tespit edilmesi ile getirilen dışarı çıkma ve seyahat kısıtlamaları gibi denetim faaliyetlerini de sınırlayacak bir takım kısıtlamalar uygulanmıştır. Ancak bu süreçte yasal veya acil ihtiyaçlara dayalı denetimlerin yapılma zorunluluğu devam etmektedir. Bazı yetki alanlarında seyahat, toplantı ve şirket sitelerine erişim kısıtlamaları ve yeterli, uygun denetim kanıtı toplamak için alternatif denetim prosedürleri geliştirme ihtiyacı denetim firmalarının bu şirketler üzerindeki denetimlerini gerçekleştirme şekillerini etkiler. Bu durum uygulanmakta olan geleneksel yerinde denetime farklı denetim yöntemleri bulma çabaları üzerinde yoğunlaşılmasına neden olmuştur. Bunun sonucunda son y1llarda endüstri 4.0'1n beraberinde getirdiği uzaktan denetim çalışmalarının uygulanması kaçınılmaz hale gelmiştir.

Salgının hızlı yayılımını önlemek amacıyla hükümetin, sağlık bakanlığ1nın, yetkili kurumların ve şirketlerin aldıkları önlemler sebebiyle finansal tabloların bağımsız denetim uygulamalarında çeşitli zorlukların yaşanmaktadır. Covid-19 nedeniyle bağımsız denetim çalışmalarında karşı karşıya kalınan zorluklar aşağıdaki gibidir (Karakaya, 2020, s. 24):

- Seyahat kısıtlaması ve şirketlerin faaliyetlerine ara verilmesiyle, uygulanan denetim tekniklerinde karşılaşılan zorluklar (Fiziki inceleme ve sayım ve gözlem prosedürleri sırasında hazırda bulunamama vb. ),

- Bazı kalemlere uygulanan doğrulamalarda yeterli ve zamanında dönüşlerin alınamaması sonucunda yeterli, uygun ve zamanında denetim kanıtı toplanamaması ve denetim çalışmalarının zamanında tamamlanamamasi,

- Uzaktan çalışma uygulaması yapan şirketlerin muhasebe sistemlerine ve denetim için ihtiyaç duyulan bilgilere ulaşılmasında zorluklarla karşılaşılması,

- Koruyucu sağlık tedbirleri nedeniyle denetim personelinin birlikte çalışamamaları ve deneyimli denetçilerin diğer çalışanlara katkıda bulunmada ve kontrolünde aksaklık yaşaması,

- Denetçinin denetim uygulamalarında bilgilerine başvurduğu şirket yönetim kurulları, şirket yetkilileri, hukuk ve bilgi sistemi uzmanlarıyla yüz yüze görüşememesi,

- Uzaktan çalışılması durumunda şirketlerin mevcut iç kontrol sistemlerinin etkinliğinin azalmış olması, 
- Şirketlerin yatırımlarının bulunduğu farklı ülkelerde karantina uygulanması durumunda grup denetimi içerisindeki diğer birim denetçilerinin çalısmalarına katkıda bulunma ve kontrol etmede karşılaşılacak sıkıntılar sebebiyle denetimlerin zamanında sonuçlandırılamaması,

- Salgınin ekonomiyi olumsuz etkilemesi nedeniyle şirketlerin finansal yapısı ve performanslarında ortaya çıkabilecek olumsuz gelişmeler nedeniyle daha fazla denetim prosedürlerinin uygulanması ihtiyacının doğmasi ve benzeri durumlar.

KGK tarafından Covid-19 salgını ile ortaya çıkan fiziki kısıtlamaların, doğrulama prosedürlerinin güvenilir bir şekilde yerine getirilmesinin zor olması olasılığı nedeniyle denetçinin doğrulama prosedürleri yazılı belgeler yerine elektronik ortamda hazırlanan güvenli belgelerle uygulaması ve şirketlerin güvenlikli sistemlerine izinli giriş sağlanarak denetim kanıtı toplaması önerilmiştir (www.kgk.gov.tr).

Günümüzde zaten Endüstri 4.0 ile birlikte denetim süreci, yazılı belgelere dayalı muhasebe sistemlerinin fiili denetiminden, sürekli elektronik olarak uzaktan denetimine doğru bir geçiş yaşanmaktadır (Kablan, 2018: s. 1571). Denetimde otomasyona odaklanarak sürekli denetim uygulamalarına geçilmiştir. Covid-19 döneminde denetimde karşılaşılacak zorluklar nedeniyle uzaktan denetim uygulamaları artırılabilir.

Uzaktan denetim, denetçilerin, finansal verilerin ve iç kontrollerin (geleneksel denetim) doğruluğunu uzaktan değerlendirmek ve raporlamak ve bilgi sisteminin sağlamlığına erişmek için bilgi ve iletişim teknolojisini veri analitiği ile birleştirdiği süreçtir (Accorsi, 2011, s. 398).

Uzaktan denetim, elektronik vasıtalar ve iletişim araçlarını kullanarak işletmenin sanal veya fiziki sahalarına ilişkin denetim faaliyetlerinin yürütülmesidir. Bir başka deyişle uzaktan denetim elektronik iletişim araçları ile denetim kanıtlarının toplanması ve uzaktaki lokasyonun (merkez, şube adresler vb.) denetlenmesi anlamına gelmektedir (https://www.avacert.com/sistemdokumanlari).

Denetçi, finansal tabloların sınırlı denetiminde bir bütün olarak finansal tablolarda önemli yanlışlık olup olmadığına dair sınırlı güvence elde etmeyi amaçlamaktadır. Bu şekilde finansal tabloların tüm önemli yönleriyle geçerli finansal raporlama çerçevesine uygun olarak hazırlanmadığ 1 fikrine ulaşmasına neden olan herhangi bir hususun dikkatini çekip çekmediğine ilişkin bir 
sonuç bildirmek ve finansal tablolara ait rapor hazırlamak ve ilgili taraflara bilgi vermektir (SBDS-2400, prg. 14).

Denetçi, finansal tablolara ait açıklayacağı denetim sonucuna temel teşkil eden yeterli ve uygun kantları toplamak için sorgulama yapar ve analitik prosedürleri uygular. Finansal tabloların önemli yanlışlık olabileceği kanaati oluştuğunda ilave prosedürleri tasarlayıp, uygulayabilir (SBDS-2400, prg. 7). Örneğin, denetçi kararlarını etkileyebilecek önemli bir sözleşmenin farkına varması durumunda ilgili sözleşmeyi inceleyebilmektedir.

Sorgulama, denetçi tarafından işletme içi veya işletme dışından olan kişilerden yazılı ve sözlü edinilen finansal ve finansal olmayan konulara dair işletme çalışanlarından veya ilişkili işletme dışındaki kişilerden bilgi alma işlemidir (Kurt, 2014, 151). Sınırlı denetimde sorgulama, yönetimden denetçinin uygun gördüğü diğer kişilerden bilgi istenmesini kapsar. (SBDS-2400, prg. A84).

Covid-19 döneminde çeşitli kısıtlamalar nedeniyle sorgulama uzaktan görüşmeler ve yazışmalar ile yapılır. Uzaktan görüşmeler, yüz yüze görüşmeyle aynı biçimde yapılır ve mevcut hazır teknolojiyi (ör. Microsoft Teams, Skype ve Zoom) kullanarak ilgili şahıslarla video görüşmeleri aracılı̆̆ıyla yapilabilir. Ayrıca e-posta ve telefon kullanılarak da sorgulama yapılabilir. Ancak denetçi tarafından bu şekilde yapılan sorgulamanın dezavantajları dikkate alınmalıdır (Teeter ve Vasarhelyi, 2010, s. 78).

Bir diğer yöntem olan analitik prosedürler ise finansal ve finansal olmayan veriler arasındaki anlamlı ilişkilerin analiz edilmesiyle finansal bilgilerin değerlendirilmesi çalışmalarıdır. Analitik prosedürler tipik olarak oranların hesaplanmasını ve bunların önceki yıllarla karşılaştıılmasını içerir. Müşterinin işini ve sektörünü daha iyi anlamak için denetimin planlama aşamasında analitik prosedürler uygulanmalıdır. Ayrıca, denetimin kanıt toplama aşamasında, mali tablolardaki olası yanlışlıkları anlamak, işlemlerin detaylarını ve hesap bakiyelerine ilişkin testlerin kapsamının azaltılmasına ilişkin gösterge sağlamak için kullanılabilirler. Ayrıca analitik prosedürler standart değerlerden oldukça farklılık veya tutarsızlık gösteren ilişkilerin gerektiğinde araştırılmasını da yardımcı olur (Rezaee vd.,2001, s. 157).

Analitik prosedürlerin basit karşılaştırmalardan ileri istatistikî teknikleri kullanarak yapılan karmaşık analizlere kadar çeşitleri mevcuttur. Örneğin denetçi, beklenen değerlerden farklılık gösteren kalemleri ve ilişkileri belirle- 
mek amaciyla analitik prosedürler uygulayabilir. Denetçi, kaydedilen tutarları veya hesaplanan oranları, topladığı bilgiler ışığında beklentileriyle karşılaştırabilir (BDS-520).

İlave prosedürler ise, denetçinin finansal tablolarda önemli yanlışlıkların olduğu fikrine ulaşmasına neden olacak durumlar hakkında bir sonuca ulaşmasını sağlayacak yeterli ve uygun kanıtın toplanmasında yardımcı olur. Denetçi Covid-19 sürecinde denetim uygulamaları sırasında karşılaşılan zorluklarda ilave prosedürler uygular. Bu prosedürler:

- Daha ayrıntılı sorgulamalar ve analitik prosedürler,

- Etkilenen kalemlere (finansal tablolara yansitilan, etkilenen hesaplara veya işlemlere ilişkin tutar veya açıklamalar gibi) yapılan ilave sorgulamalar ve analitik prosedürler veya

- Maddi doğrulama prosedürlerinden detay testleri veya doğrulama gibi diğer prosedür türleri, olabilir (SBDS-2400, prg, A104).

\section{Sınırlı Bağımsız Denetim Raporu}

Denetçi sınırlı denetim sonucunda, işletmenin finansal tablolarının finansal raporlama ilkelerine uygun olarak hazırlanıp hazırlanmadığı konusunda kullanıcıların güvenini artırmayı hedefleyen bir rapor hazırlar. Denetçinin raporunda sunduğu sonuç, denetçinin ara dönem denetim çalışmaları sonucunda elde ettiği sınırlı güvenceye dayanır. Denetçi raporunda, kullanıcılarının denetim sonucunu anlayabilmelerini sağlamak amacıyla sınırlı denetimin niteliğine ait bir açıklamaya yer verilir (SBDS-2400, prg. 6). Sınırlı denetim sonucunda denetçi, ara dönem finansal bilgilerin, finansal durumunun, finansal performansının ve aynı tarihte sona eren üç aylık döneme ilişkin nakit akışlarının Türkiye Muhasebe Standartlarına uygun olarak, doğru ve gerçeğe uygun bir görünümünü sağlamadığı sonucuna ulaşmasına neden olacak herhangi bir hususun dikkat çekmediğini bildirir. Ancak ara dönem finansal bilgileri inceleyen denetçi finansal raporlama çerçevesine uygun bir düzeltme yapılmasını gerekli görürse şartlı veya olumsuz bir sonuç bildirir.(SBDS 2410, prg. 45)

Denetçinin ara dönem finansal tablolarına ilişkin hazırladığı sınırlı bağımsız denetim raporu aşağıdaki unsurları içerir (www.spk.gov.tr; SBDS-2410, prg. 43).

1. Denetim raporunun başlığ1

2. Denetimin muhatabı. 
3. Genel amaçlı tam set veya özet ara dönem finansal tablolar kapsamındaki her bir tablonun başlığı, ilgili olduğu dönem ve/veya tarihi,

4. Ara dönem finansal bilgilerin geçerli finansal raporlama çerçevesine uygun olarak hazırlanmasından ve gerçeğe uygun sunumundan yönetimin sorumlu olduğunun belirtilmesi,

5. Sınırlı denetime dayanarak ara dönem finansal bilgilere ilişkin bir sonuç bildirme sorumluluğunun denetçiye ait olduğunun belirtilmesi,

6. Ara dönem finansal bilgilere iliş̧kin sınırlı denetimin, Sınırlı Bağımsız Denetim Standardı (SBDS) 2410, “Ara Dönem Finansal Bilgilerin, İşletmenin Yıllık Finansal Tablolarının Bağımsız Denetimini Yürüten Denetçi Tarafından Sınırlı Bağımsız Denetimine" uygun olarak yürütüldüğünün ve bu tür bir sınırlı denetimin, başta finans ve muhasebe konularından sorumlu kişiler olmak üzere ilgili kişilerin sorgulanması ve analitik prosedürler ile diğer sınırlı denetim prosedürlerinin uygulanmasından oluştuğunun ifade edilmesi,

7. Sınırlı denetimin kapsamının, bağımsız denetimin kapsamına göre önemli ölçüde dar olduğunun ve denetçinin, bir bağımsız denetimde belirlenebilecek tüm önemli hususları belirleyebileceğine ilişkin bir güvence elde edemediğinin ve bu sebeple bir bağımsız denetim sonucu bildirmediğinin ifade edilmesi,

8. Ara dönem finansal tablolar tam set finansal tablolardan oluşuyorsa, bu finansal tabloların şirketin durumunu doğru ve dürüst bir biçimde yansitmadığı veya finansal raporlama standartlarına uygun olarak sunulmadığına ilişkin bağımsız denetçinin dikkatini çeken bir durumun olup olmadığının ifade edilmesi,

9. Diğer durumlarda, denetçinin ara dönem finansal tablolardaki bilgilerin, tüm önemli yönleriyle, finansal raporlama ilkelerine uygun olarak hazırlanmadığı sonucuna ulaşmasına neden olacak herhangi bir hususun dikkatini çekip çekmediğinin ifade edilmesi,

10. Denetçi raporunun tarihi,

11. Bağımsız denetim kuruluşunun adresi ve sorumlu ortak baş denetçinin adı ve soyadı,

12. Sorumlu ortak baş denetçinin imzası.

13. Ayrıca TÜRMOB (2020) koronavirüs salgını üzerine yaptığı çalışmasında denetçilerin raporlarında yer verebilecekleri bazı hususlara yer vermiştir. Bunlar (TÜRMOB, 2020: s. 11); 
- Kamu yararını ilgilendiren kuruluşlar için koronavirüs salgını nedeniyle ihtiyaç duyulabilecek grup denetim yaklaşımları, önemli belirsizlik ya da işletmenin sürekliliği üzerine ilave bir denetim çalışması yapılması,

- İşletmenin sürekliliği ile ilgili önemli belirsizlik açıklaması,

- Covid-19 salgını nedeniyle "dikkat çeken hususlar" paragrafına yer verilmesi,

- Dipnotlardaki açıklamaların yetersizliği ya da işletmenin sürekliliği hususunda olumsuz sonuç bildirilmesi,

- Durum değerlendirilmelerine şahsi olarak katılamama nedeniyle, uygun denetim kanıtlarına ulaşılamaması etkisiyle şartlı bir görüş veya olumlu görüş dışında bir görüşün verilmesidir.

\section{Yöntem}

Çalışmada BIST 100 endeksinde işlem gören şirketlerin 1 Ocak- 30 Haziran 2020 ara hesap dönemine ait finansal tabloları ve sınırlı denetim raporları Kamuyu Aydınlatma Platformunun (KAP) internet sitesinden elde edilerek incelenmiştir. Çalışmamızın ana kütlesini, ara dönem finansal raporlarını yayınlayan 100 şirket oluşturmuştur. Dolayısıyla araştırmamıza konu olan 100 şirketin sınırlı denetim raporları ve finansal tabloları dipnotlarıyla ayrıntılı incelenmiştir.

Bu çalışmanın amacı Covid-19'un bağımsız denetim sürecine etkilerini incelenmek ve sınırlı denetim raporlarında Covid-19 etkilerine ne ölçüde yer verdiklerini saptamaktır. Çalışmada sınırlı denetim raporunda Covid-19 ile ilgili bilgilere yer veren beş şirketin sınırlı denetim rapor örneklerine de yer verilmiştir. Böylece denetim alanında hizmet veren şirketlere ve denetçilerin faaliyetlerine katkı sağlanması amaçlanmıştır.

\section{Bulgular}

Araştırmamıza ara dönem finansal raporlarında sınırlı denetim raporuna yer veren 100 şirketin denetim sektörleri itibariyle hizmet aldıkları denetim şirketleri Tablo 1'de yer almaktadır Çalışmada denetim şirketleri sınıflandırılırken, literatürde "4 Büyükler (Big Four)" olarak adlandırılan Ernst\&Young, PwC, Deloitte ve KPMG şirketleri ve diğer denetim şirketleri olarak sinıflandırılmıştır. Buna göre söz konusu şirketlerin $\% 85^{\prime}$ lik kısmının 4 Büyükler olarak adlandırılan denetim şirketlerinden hizmet aldıkları belirlenmiştir. 
Tablo 1. Sektörel itibariyle denetim şirketlerinin faaliyet konularn

\begin{tabular}{lccc}
\hline Sektörler & Dört büyükler & Diğer denetim şirketleri & Toplam \\
\hline İmalat & 32 & 7 & 39 \\
\hline Mali Kuruluşlar & 32 & 1 & 33 \\
\hline Ulaştırma, Depolama ve Haberleşme & 4 & & 4 \\
\hline Elektrik Gaz ve Su & 3 & 2 & 5 \\
\hline Toptan ve Perakende Ticaret, Lokantalar ve Oteller & 6 & 1 & 7 \\
\hline Kimya İlaç Petrol Lastik ve Plastik Ürünler & 1 & 3 & 1 \\
\hline Teknoloji & 2 & & 5 \\
\hline İnşaat ve Bayındırlık & 1 & 1 & 1 \\
\hline Gayrimenkul Faaliyetleri & & & 1 \\
\hline Madencilik ve Taş Ocakçlı̆̆ı & 3 & & 3 \\
\hline Ĕgitim, Sağlık, Spor ve Diğer Sosyal Hizmetler & 1 & 15 & 1 \\
\hline Toplam & 85 & & 100 \\
\hline
\end{tabular}

Bilindiği gibi sınırlı bağımsız denetim raporu, finansal bilgilerin Türkiye Muhasebe Standartlarına uygun olarak, doğru ve gerçeğe uygun bir görünümünü sağlamadığı sonucuna ulaşmasına neden olacak herhangi bir hususun dikkat çekmediğini açıklar. Eğer finansal raporlama çerçevesine uygun bir düzeltme yapılmasını gerekli görürse şartlı veya olumsuz bir sonuç bildirir. Tablo 2' de 1 Ocak- 30 Haziran 2020 tarihli ara hesap dönemi sinılı denetim raporunu yayımlayan 100 şirkete ait bağımsız denetçilere ait sonuçlar yer almaktadır. Buna göre şirketlerin büyük çoğunluğunun raporlarında "olumlu görüş̧" aldıkları belirlenmiştir. Yani denetçi finansal bilgilerin Türkiye Muhasebe Standartlarına uygun olarak, doğru ve gerçeğe uygun bir görünümünü sağlamadığı sonucuna ulaşmasına neden olacak herhangi bir hususun dikkat çekmediğini sonucuna ulaşmışlardır.

Tablo 2. Denetçi sonuçlan

\begin{tabular}{lc}
\hline Denetçi sonuçları & Şirket sayısı \\
\hline Olumlu görüş & 86 \\
\hline Şartlı görüş & 14 \\
\hline Toplam & 100 \\
\hline
\end{tabular}

Çalışmamızın bu bölümünde BİST 100 Endeksinde işlem gören 100 şirketin tamamina ait finansal raporları incelenerek, Covid-19 ile ilgili yapılan açıklamalar Tablo 3'te derlenmiştir. Bunun nedeni söz konusu şirketlerin ara dönem finansal tabloları denetimden geçmeyen şirketlerin de finansal raporlarında Covid-19 ile ilgili açıklamalara yer vermiş olduklarının tespit edilmesidir. Dolayısiyla Tablo 3'te toplam 99 şirketin ara dönem finansal tablolarında Covid-19 ile ilgili bilginin paylaşıldığ bölümler yer almaktadır. Buna 
göre 99 şirketin 81 tanesinin Covid-19’a “Finansal Tabloların Sunumuna İlişkin Esaslar" bölümünde yer verdikleri görülmektedir.

Tablo 3. Covid-19 ile ilgili bilginin paylaşıldı̆̆ı bölümler

\begin{tabular}{lc}
\hline Konu başlı̆̆ı & Şirket sayısı \\
\hline Finansal Tabloların Sunumuna İlişkin Esaslar & 81 \\
\hline $\begin{array}{l}\text { Finansal tabloları önemli ölçüde etkileyen ya da finansal tabloların açık, yorumlana- } \\
\text { bilir ve anlaşılabilir olması açısından açılanması gereken diğer hususlar }\end{array}$ & 15 \\
\hline Önemli Muhasebe Politikaları & 10 \\
\hline Sermaye, Yedekler ve Diğer Özsermaye Kalemleri & 7 \\
\hline Bilanço (Raporlama) Tarihinden Sonraki Olaylar & 6 \\
\hline Şirketin Organizasyonu ve Faaliyet Konusu & 4 \\
\hline Yatırım Amaçlı Gayrimenkuller & 2 \\
\hline Finansal Borçlanmalar & 1 \\
\hline Finansal Araçlara İlişkin Açıklamalar & 2 \\
\hline Diğer Açıklamalar & 13 \\
\hline
\end{tabular}

Tablo 3'te yer alan 7 şirket Covid-19 ile ilgili bilginin paylaşıldı̆̆ bölümlerden "Sermaye, Yedekler ve Diğer Özsermaye Kalemleri"ne ara dönem finansal raporlarında yer vermişlerdir. Bu bölüm 17 Nisan 2020 tarihinde "7244 sayılı Yeni Koronovirüs Salgınının Ekonomik ve Sosyal Hayata Etkilerinin Azaltılması Hk. Kanun" ile eklenen geçici maddenin sermaye şirketlerinde kar dağıtımına dair getirdiği sınırlamaya ilişkindir. Bu kanuna göre; 30 Eylül 2020 tarihine kadar 2019 yılı net dönem karının yalnızca yüzde yirmi beşine kadarını şirketler kar payı olarak dağıtılabilecek, geçmiş yıl karları ve serbest yedek akçeler dağıtıma dahil edilmeyecektir.

Finansal Tabloların Sunumuna İlişkin Esaslar bölümünde Covid-19'un geçtiği konulara ayrı ayrı kalemler halinde Tablo 4 'te yer verilmiştir. Buna göre araştırmamıza konu olan şirketlerin finansal raporlarının büyük çoğunluğunda "Kira Ödemelerinde Tanınan İmtiyazlar" konusunun yer aldığı görülmektedir.

Tablo 4. Finansal tabloların sunumuna ilişkin esaslarda Covid-19'un geçtiği konular

\begin{tabular}{llc}
\hline Konu Başlığı & Bölümler & Şirket Sayısı \\
\hline & Kira Ödemelerinde Tanınan İmtiyazlar & 76 \\
\cline { 2 - 3 } Finansal & Cari Döneme İlişkin Önemli Gelişmeler & 34 \\
\cline { 2 - 3 } Tabloların & İşletmenin Sürekliliği & 7 \\
\cline { 2 - 3 } $\begin{array}{l}\text { Sunumuna } \\
\text { Illişkin }\end{array}$ & Covid-19/ Covid-19 Pandemisi/ Covid-19'un Finansal Tablolar Üzerindeki Etkileri & 7 \\
\cline { 2 - 3 } Esaslar & Covid-19'un Grup Faaliyetlerine Etkisi & 6 \\
\cline { 2 - 3 } & Önemli Muhasebe Değerlendirme, Tahmin ve Varsayımları & 1 \\
\cline { 2 - 3 } & Ertelenen vergi ve diğer yükümlülükler & 1 \\
\cline { 2 - 3 } & Operasyonları Etkileyen Olaylar & 6 \\
\hline
\end{tabular}


KGK tarafından 5 Haziran 2020 tarihinde “Covid 19'la İlgili Olarak Tan1nan Kira İmtiyazları-TFRS 16'ya İlişkin Değişiklikler" in yayımlanmıştır. Buna göre; bu uygulama sadece kira ödemelerinde Covid-19 salgını nedeniyle tanınan imtiyazlar olup, şu koşulların sağlanmasıyla uygulanabilmektedir;

- Kira ödemelerinde oluşan değişikliğin kiralama bedelinin yeniden düzenlenmesine sebep olması ve yeni bedelin, değişiklikten hemen önceki kiralama bedeliyle aynı veya söz konusu bedelden daha düşük olması,

- Kira ödemelerinde oluşan azalışın, sadece normalde vadesi 30 Haziran 2021 veya öncesinde dolan ödemeleri etkilemesi,

- Kiralamanın diğer hüküm ve koşullarında önemli ölçüde bir değişikliğin olmamasi.

Yapılan değişiklikle kiracılara sağlanan bu muafiyetle birlikte kullanım varlığının ve kira yükümlülüğünün yeniden ölçülmesine gerek olmamaktadır. İleriki vadede kira ödemelerinde indirim veya süre değişiklikleri kiralamalarda yapılan bir değişiklik olarak nitelendirilecektir.

Ayrıca 34 şirketin ara dönem finansal raporlarında Covid-19'dan "Cari Döneme İlişkin Önemli Gelişmeler" bölümüne yer verdiği görülmektedir. Yapılan incelemelerde şirketlerin bu bölümde Covid-19 nedeniyle şirketlerindeki değer düşüklüklerini değerlendirdikleri ve varsa gerekli düzeltmeleri yaptıklarına dair bilgi verdikleri tespit edilmiştir.

\section{Stnırh Denetim Raporunda Covid-19 ile İlgili Bilgilere Yer Veren Denetçi Rapor Örnekleri}

Çalışmamızın bu bölümünde şirketlerin 1 Ocak-30 Haziran 2020 ara hesap dönemine ait denetçi raporlarında Covid-19 ile ilgili açıklamalar içeren şirketlerin raporlarına yer verilmiştir. BIST 100'de işlem gören ve ara dönem finansal raporlarında sınırlı denetim raporunu yayınlayan 100 şirketten sadece 5 adedinin denetçi raporlarında Covid-19'a yer verdiği tespit edilmiştir. $\mathrm{Bu}$ şirketlerden 4 tanesinin 4 Büyük denetim şirketinden hizmet aldığı görülmektedir. 
Covid 19 Sürecinde Sınırlı Bağımsız Denetim ve BIST 100 Şirketleri Üzerine Bir Araştırma

\begin{tabular}{|c|c|}
\hline \multicolumn{2}{|c|}{ Karsan Otomotiv Sanayii ve Ticaret AŞ. } \\
\hline Bağımsız Denetim Şirketi & DELOITTE \\
\hline Bağımsız Denetim Tarihi & 29.07 .2020 \\
\hline $\begin{array}{ll}\text { Bağımsız } & \text { Denetim } \\
\text { Görüşü } & \\
\end{array}$ & Şartlı Görüş \\
\hline $\begin{array}{l}\text { Denetim Raporunda } \\
\text { Covid-19 Etkisi }\end{array}$ & Şirket Değerinin Belirlenmesinde Meydana Gelen Gecikme \\
\hline \begin{tabular}{lrr} 
Denetim & \multicolumn{2}{c}{ Raporunda } \\
Covid-19 & ile & İlgili \\
Açıllama & & \\
\end{tabular} & $\begin{array}{l}\text { Şirket, } 2018 \text { ve } 2019 \text { yılları içinde sermaye artışlarına katılmak } \\
\text { suretiyle Industria Italiana Autobus'da ("IIA”) bulunan } \\
\text { yatırım tutarını } 26.927 \text { bin TL'den } 78.635 \text { bin TL'ye çlkartmıştır. } \\
\text { Son olarak } 24 \text { Şubat } 2020 \text { tarihinde yaptığ } 125 \text { bin TL tutarın- } \\
\text { daki sermaye ödemesi ile toplam yatıım tutarını } 78.760 \text { bin } \\
\text { TL'ye çıkartmış ve IIA'nı \% } 28,59 \text { 'luk hisse alımı } \\
\text { tamamlamıştır. TFRS 3'ün gerektirdiği doğrultuda alıma konu } \\
\text { olan şirketin değerinin belirlenmesi ve satın alım fiyatının ilgili } \\
\text { bilanço kalemlerine dağıtılması için bağımsız bir değerleme } \\
\text { kuruluşu çalışmalara başlamış ancak ilgili çalışma, Covid-19 } \\
\text { virüsünün küresel salgın olarak tüm dünyayı etkisi altına al- } \\
\text { masına bağlı olarak ara dönem çalışmalarına yetişmemiştir. Bu } \\
\text { nedenle } 78.760 \text { bin TL'lik geçici şerefiye tutarı finansal } \\
\text { tablolarda, finansal yatırımlar kalemi altında gösterilmeye de- } \\
\text { vam edilmiştir. Değerleme çalışmasının bu yılsonuna kadar } \\
\text { bitmesi beklenmekte olup, gerekli düzeltmelerin } 31 \text { Aralık } \\
2020 \text { finansal tablolarına yansıtılmasi hedeflenmektedir. }\end{array}$ \\
\hline $\begin{array}{l}\text { Faaliyet Raporunda } \\
\text { Covid-19 ile İlgili Konu }\end{array}$ & $\begin{array}{l}\text { *Işletmenin Sürekliliği Varsayımı } \\
{ }^{*} \text { Covid-19 ile İlgili Olarak Kira Ödemelerinde Tanınan } \\
\text { İmtiyazlar }\end{array}$ \\
\hline
\end{tabular}

\begin{tabular}{|l|l|}
\hline \multicolumn{2}{|l|}{ TAV Havalimanları Holding A.Ş. } \\
\hline Bağımsız Denetim Şirketi & ERNST \& YOUNG \\
\hline Bağımsı Denetim Tarihi & 24.07 .2020 \\
\hline $\begin{array}{l}\text { Bağımsız Denetim } \\
\text { Görüşü }\end{array}$ & Olumlu Görüş̧ \\
\hline $\begin{array}{l}\text { Denetim Raporunda } \\
\text { Covid-19 Etkisi }\end{array}$ & Dikkat Çekilen Husus - Covid 19 Salgınıla İlgili Belirsizlik \\
\hline $\begin{array}{l}\text { Denetim Raporunda } \\
\text { Covid-19 ile İlgili } \\
\text { Açıklama }\end{array}$ & $\begin{array}{l}\text { Son zamanlarda küresel olduğu kadar bölgesel olarak da } \\
\text { ekonomik koşulları olumsuz etkileyen Covid-19 salgınının, } \\
\text { Grup'un faaliyetlerini aksattığını ve bu salginın nihai etkisinin } \\
\text { şu an itibariyle belirsiz olması nedeniyle Grup'un faaliyetleri } \\
\text { üzerindeki etkisinin makul bir şekilde tahmin edilemediğini } \\
\text { açıklayan 1 no'lu finansal tablo dipnotuna dikkat çekeriz. An- } \\
\text { cak bu husus tarafımızca verilen görüšü etkilememektedir. }\end{array}$ \\
\hline $\begin{array}{l}\text { Faaliyet Raporunda } \\
\text { Covid-19 ile İlgili Konu }\end{array}$ & $\begin{array}{l}\text { *Covid-19 ile İlgili Olarak Kira Ödemelerinde Tanınan } \\
\text { İmtiyazlar } \\
{ }^{*} \text { Covid-19 etkileri ve değer düşüklüğü analizi } \\
\text { *Finansal Borçlanmalar }\end{array}$ \\
\hline
\end{tabular}




\begin{tabular}{|c|c|}
\hline \multicolumn{2}{|c|}{ Pegasus Hava Taşımacılığı A.Ş. } \\
\hline Bağımsız Denetim Şirketi & ERNST \& YOUNG \\
\hline Bağımsız Denetim Tarihi & 12.08 .2020 \\
\hline $\begin{array}{l}\text { Bağımssiz } \\
\text { Görüsü }\end{array}$ & Olumlu Görüş \\
\hline $\begin{array}{l}\text { Denetim Raporunda } \\
\text { Covid-19 Etkisi }\end{array}$ & Dikkat Çekilen Husus \\
\hline \begin{tabular}{lrr} 
Denetim & \multicolumn{2}{l}{ Raporunda } \\
Covid-19 & ile & İlgili \\
Açılama & &
\end{tabular} & $\begin{array}{l}\text { Son zamanlarda küresel olduğu kadar bölgesel olarak da } \\
\text { ekonomik koşulları olumsuz etkileyen Covid-19 salgınının, } \\
\text { Grup'un faaliyetlerini aksattığı ve bu salgının nihai etkisinin } \\
\text { şu an itibariyle belirsiz olması nedeniyle Grup'un faaliyetleri } \\
\text { üzerindeki etkisinin makul bir şekilde tahmin edilemediğini } \\
\text { açılayan } 2.5 \text { numaralı finansal tablo dipnotuna dikkat çekeriz. } \\
\text { Ancak bu husus tarafımızca verilen görüşü etkilememektedir. }\end{array}$ \\
\hline $\begin{array}{l}\text { Faaliyet Raporunda } \\
\text { Covid-19 ile İlgili Konu }\end{array}$ & $\begin{array}{l}{ }^{*} \text { Covid-19 ile İlgili Olarak Kira Ödemelerinde Tanınan } \\
\text { İmtiyazlar } \\
{ }^{*} \text { Operasyonları Etkileyen Olaylar }\end{array}$ \\
\hline
\end{tabular}

\begin{tabular}{|l|l|}
\hline \multicolumn{2}{|l|}{ Mavi Giyim Sanayi ve Ticaret A.Ş. } \\
\hline Bağımsız Denetim Şirketi & DELOITTE \\
\hline Bağımsız Denetim Tarihi & 14.09 .2020 \\
\hline $\begin{array}{l}\text { Bağımsız Denetim } \\
\text { Görüşü }\end{array}$ & Olumlu Görüş \\
\hline $\begin{array}{l}\text { Denetim Raporunda } \\
\text { Covid-19 Etkisi }\end{array}$ & Önemli Belirsizlik - Covid-19 \\
\hline $\begin{array}{l}\text { Denetim Raporunda } \\
\text { Covid-19 ile İlgili } \\
\text { Açıklama }\end{array}$ & $\begin{array}{l}\text { Covid-19 salgını Grup'un faaliyetlerini etkilemiştir. Yönetim, } \\
\text { Covid-19'un faaliyetleri ve bunun üzerindeki planları üzerin- } \\
\text { deki etkisini finansal tabloların 26. notunda açılamıstır. Grup } \\
\text { yönetimi, Covid-19'un Şirket'in finansal performansı üzerin- } \\
\text { deki etkisinin kesin bir tahminin yapılmasının mümkün olma- } \\
\text { dığını belirtmektedir. Bu husus, tarafımızca verilen sınırlı de- } \\
\text { netim sonucunu etkilememektedir. }\end{array}$ \\
\hline $\begin{array}{l}\text { Faaliyet Raporunda } \\
\text { Covid-19 ile İlgili Konu }\end{array}$ & $\begin{array}{l}{ }^{*} \text { Cari Döneme İlişkin Önemli Gelişmeler } \\
\text { *Covid-19 ile İlgili Olarak Kira Ödemelerinde Tanınan } \\
\text { İmtiyazlar }\end{array}$ \\
${ }^{*}$ Finansman Gelirleri \\
\hline
\end{tabular}

\begin{tabular}{|l|l|}
\hline \multicolumn{2}{|l|}{ İndeks Bilgisayar Sistemleri Mühendislik Sanayi ve Ticaret A.Ş. } \\
\hline Bağımsız Denetim Şirketi & Abaküs Bağımsız Denetim A.Ş. \\
\hline Bağımsı Denetim Tarihi & 17.08 .2020 \\
\hline $\begin{array}{l}\text { Bağımsız Denetim } \\
\text { Görüşü }\end{array}$ & Olumlu Görüş \\
\hline $\begin{array}{l}\text { Denetim Raporunda } \\
\text { Covid-19 Etkisi }\end{array}$ & Diğer Husus \\
\hline
\end{tabular}




\begin{tabular}{|c|c|}
\hline \begin{tabular}{llr} 
Denetim & \multicolumn{2}{c}{ Raporunda } \\
Covid-19 & ile & İlgili \\
Açılama & &
\end{tabular} & $\begin{array}{l}\text { Çin'de ortaya çıkan ve } 2020 \text { yılında tüm dünyaya yayılan Dü- } \\
\text { nya Sağlık Örgütü (WHO) tarafından pandemi olarak ilan } \\
\text { edilen Covid-19 virüsünün insan sağlığının yanı sıra, üretim, } \\
\text { ticaret ve ulaşım gibi birçok alanda kısıllayııı etkileri olmuştur. } \\
\text { Bu kısıtlayıcı etkiler sonucunda } 2020 \text { yılında dünya çapında } \\
\text { ekonomik olarak resesyon beklentisi oluşmuştur. Grup yöne- } \\
\text { timi bu durumun ekonomik etkilerini en alt seviyeye indire- } \\
\text { bilmek için gerekli önlemleri almakta olup, salgın dolayısıyla } \\
\text { oluşması beklenen ekonomik küçülmenin finansal tablolara } \\
\text { etkisi tam olarak tespit edilememektedir. Grup'un konsolide } \\
\text { finansal tabloları işletmenin sürekliliği varsayımına göre hazır- } \\
\text { lanmış olup, salgın nedeniyle ortaya çıkabilecek düzeltme ve } \\
\text { sınıflandırmayı içermemektedir. Grup yönetiminin konu ile } \\
\text { ilgili açıklamalarına Not:41'de yer verilmiştir. Bu husus } \\
\text { tarafımızca verilen görüsü etkilememektedir. }\end{array}$ \\
\hline $\begin{array}{lr}\text { Faaliyet } & \text { Raporunda } \\
\text { Covid-19 ile İlgili Bölüm }\end{array}$ & $\begin{array}{l}\text { Dipnot } 41 \text { Finansal Tabloları Önemli Ölçüde Etkileyen Diğer } \\
\text { Hususlar }\end{array}$ \\
\hline
\end{tabular}

\section{Sonuç}

2019 yılı sonunda Çin'in Vuhan kentinde ortaya çıkan ve Dünya Sağlık Örgütü tarafından pandemi ilan edilen koronavirüs nedeniyle ülkeler birçok alanda çeşitli kısıtlamalar getirmiştir. Bu kısıtlamalar şirketler üzerinde önemli ekonomik etkilere neden olmuştur. Kısıtlamaların, şirketlerin ve diğer kurumların muhasebesi, raporlaması ve denetimi üzerinde olumsuz etkileri görülmüştür.

Bu çalışmanın amacl; BİST 100 endeksinde işlem gören şirketlerin 1 Ocak30 Haziran 2020 ara hesap dönemine ait finansal tabloları ve sinılı denetim raporlarında Covid-19'un bağımsız denetim sürecine etkilerini saptamak ve sınırlı denetim raporlarında Covid-19 etkilerine ne ölçüde yer verdiklerini ortaya koymaktır.

Çalışma sonucunda BİST 100 Endeksinde işlem gören 100 şirketin tamamına ait finansal raporlar incelenerek, Covid-19 ile ilgili yapılan açıklamalara 81 şirketin "Finansal Tabloların Sunumuna İlişkin Esaslar" bölümünde yer verdikleri görülmüştür. Ayrıca ara dönem finansal raporlarında sınırlı denetim raporuna yer veren 100 şirketin büyük çoğunluğunun 4 Büyükler olarak adlandırılan denetim şirketlerinden hizmet aldıkları belirlenmiştir. Şirketlerin büyük çoğunluğunun raporlarında Türkiye Muhasebe Standartlarına uygun olarak, doğru ve gerçeğe uygun bir görünümünü sağlamadığı sonucuna 
ulaşmasına neden olacak herhangi bir hususun dikkat çekmediği ifade edilmiştir.

Finansal Tabloların Sunumuna İlişkin Esaslar bölümünde Covid-19'un geçtiği konulara ayrı ayrı incelendiğinde, araştırmamıza konu olan şirketlerin finansal raporlarının büyük çoğunluğunda "Kira Ödemelerinde Tanınan İmtiyazlar" konusuna yer verdiği tespit edilmiştir. Ayrıca 34 şirketin de ara dönem finansal raporlarında "Cari Döneme İlişkin Önemli Gelişmeler" bölümünde şirketlerindeki değer düşüklükleri değerlendirmelerine ilişkin açıklamalara yer verdikleri görülmüş̧ür.

Finansal raporlarında sınırlı denetim raporu yayımlayan şirketlerden sadece 5 şirketin denetçi raporlarında Covid-19'a ilişkin açıklamalara yer verdikleri tespit edilmiştir. Bu şirketlerden de 4 tanesinin 4 Büyük denetim şirketinden hizmet aldığ görülmektedir. Sınırlı denetim raporunda Covid19 'un etkilerine yer veren şirketlerin büyük çoğunluğu “Dikkat Çekilen Husus" başlığ 1 altında, Covid-19 nedeniyle yaşanan belirsizliklere yer vermiştir. Ayrıca bu raporlarda Covid-19 etkisiyle şirket değerlemesinde yaşanan gecikmelere de yer verilmiştir. Sınırlı denetim raporunda Covid-19 etkisine yer veren bir diğer şirket ise pandemi nedeniyle yaşanması muhtemel olan resesyona dikkat çekmiştir.

Covid-19 etkisine sınırlı denetim raporlarında yer veren bu beş şirket raporlarında, denetim sırasında Covid-19 nedeniyle uzaktan denetim tekniklerinden yararlanup yararlanmadıklarına ilişkin herhangi bir ek ifadeye yer vermemiştir. Yine bu raporlarda pandemi nedeniyle ek denetim tekniklerine başvurduklarına dair bir açıklamaya da rastlanmamıştır.

Covid-19 pandemisi döneminde getirilen kıstlamalar, uzaktan denetime olan ihtiyacın önemini ortaya çıkarmıştır. Endüstri 4.0 ile birlikte kullanılan uzaktan denetim tekniklerinin bu süreçte denetim faaliyetlerini kolaylaştırdığı görülmüş̧ür. Denetim raporlarının taraflara daha doğru ve güvenilir bilgiler sunması için denetçilerin uzaktan denetim tekniklerinde daha titiz davranmaları ve Covid-19 etkilerine ara dönem finansal raporlarında ve sınırlı denetim raporlarında da daha fazla yer vermeleri gerektiği kanaatindeyiz. 


\title{
EXTENDED ABSTRACT
}

\section{Review of Financial Statement in the Covid-19 Process and a Research on BIST-100 Companies Article}

\author{
Mehtap Karakoç - Meral Gündüz \\ Uşak University-Uşak University
}

Due to the coronavirus, which emerged in Wuhan, China at the end of 2019 and was declared a pandemic by the World Health Organization, countries have imposed various restrictions in many areas. These restrictions have caused significant economic impacts on companies and these negative effects continue. The accounting systems, financial reports and audits of the companies were also affected by these negativities.

In Turkey, The Union of Chambers of Certified Public Accountants of Turkey (TURMOB) has issued implementation recommendations to the auditors for the audit of financial statements. In these recommendations, it has been stated that companies and auditors may encounter some difficulties in the implementation of audit activities and they should improve the procedures they apply due to restrictions encountered in travel, meetings and accessing companies' websites. For example, it should be considered whether there is a need for alternative audit procedures to be used in places with travel restrictions (TÜRMOB, 2020, p.12-13).

In addition, the Public Oversight, Accounting and Auditing Standards Authority (KGK) has also stated in its issued explanation that in the Covid-19 period, due to restrictions on travel and company visits, auditors should consider alternative methods to collect sufficient and appropriate audit evidence in cases where audit evidence cannot be obtained in the planned quality and time. According to this statement, the indispensability for the auditor to review which items the physical examination is important in testing and how it should be carried out have been stated. It has been also stated that whether the timing of the various decisions to be taken by the auditor and the timing of some audit procedures have a sig- 
nificant effect and that the effects on the auditor's opinion of failing to fulfill important procedures on time due to restrictions may be required to be evaluated (www.kgk.gov.tr).

Banks and private financial institutions and companies operating in the capital market are obliged to subject their financial statements to a review of financial statement and to prepare these interim financial statements as of the end of the 3rd, 6th and 9th months and to send them to the Banking Regulation and Supervision Agency (BDDK) and the Capital Markets Board (SPK). These statements made by TÜRMOB and KGK regarding the audit during the Covid-19 period are also valid for the interim review of financial statement

In Turkey, Auditing Standards of Turkey, issued by KGK, grounds on the standards issued by the International Federation of AccountantsIFAC. The Review of financial statement Regulation published in 2012 with the adoption of the Turkish Commercial Code numbered 6102 explains Auditing Standards of Turkey as the standards of training, ethics, quality control and auditing in accordance with international auditing standards, and other regulations in this area (KGK, 2019, p. 1).

KGK defines the review of financial statement as a type of audit that provides its users with a limited level of assurance in terms of the reliability of historical financial information (KGK, 2019: p.2). On the other hand, SPK expresses the review of financial statement as the reporting that "there are no material misstatements related to the financial statements" by first investigating the compliance of the financial statements with the financial reporting standards published by the Board and by examining them with the help of analytical examination techniques. Thus, it is ensured that the financial reports of the enterprises for the interim periods are examined (SPK Serial X, No: 22, Section 34 ).

The objective of the review of financial statement of interim financial information differs from the audit objective applied according to independent audit standards. The review of financial statement of interim financial information does not allow for the statement of a conclusion on the fair presentation of financial information in all its dimensions (SBDS 2410, prg. 8). 
As a result of the review of financial statement, the auditor prepares a report aiming to increase the confidence of the users on whether the financial statements of the company are prepared in accordance with the financial reporting principles. In this report, it states that nothing attracts attention to the conclusion that the interim financial information, financial position, financial performance, and cash flows for the three-month period ending on the same date do not provide an accurate and fair view in accordance with The Turkish Accounting Standards. However, if the auditor who examines the interim financial information deems it necessary to make an adjustment in accordance with the financial reporting framework, s/he will report a conditional or adverse result. (SBDS 2410, prg. 45)

In this study, theoretical information about the review of financial statement was given and the financial statements and the review of financial statement reports of the companies included in the Borsa Istanbul 100 index (BIST-100) for the interim period between January 1- June 30, 2020, were examined. To what extent these BIST-100 companies are affected by Covid-19 and to what extent they include these effects in their interim financial statements and review of financial statement reports were investigated. The study is important in that no similar study has been conducted in the literature regarding the review of financial statement. The aim of this study is to determine the effects of Covid-19 on the review of financial statement process in the financial statements and the review of financial statement reports of the companies traded in the BIST 100 index for the interim fiscal period from January 1 to June 30, 2020, and to reveal the extent to which they include Covid-19 effects in the review of financial statement reports.

As a result of the study, the financial reports of all 100 companies traded in the BIST 100 Index were examined and it was seen that 81 companies included the explanations about Covid-19 in the "Principles Regarding Presentation of Financial Statements" section. In addition, it was determined that the majority of the 100 companies that included review of financial statement reports in their interim financial reports received services from audit companies called Big Four. It has been stated in the reports of the majority of the companies that no issue that leads to the conclusion that it does not provide an accurate and fair view in accordance with the Turkish Accounting Standards draws attention. 
When the subjects which have mentioned Covid-19 in the Principles Regarding Presentation of Financial Statements section were examined separately, it was found that the majority of the financial reports of the companies subject to our study included the subject of "Privileges Granted in Rental Payments." In addition, it was seen that 34 companies included explanations regarding the assessments of the impairment of their companies in the "Significant Developments Regarding Current Period" section of their interim financial reports.

It was determined that among the companies that publish review of financial statement reports in their financial reports, only 5 companies include explanations regarding Covid-19 in their auditor reports. It was seen that of these companies, 4 received service from the Big Four audit companies. Most of the companies, which included the effects of Covid-19 in the review of financial statement report, included the uncertainties due to Covid-19 under the title "Subject To Consider." In addition, these reports also included delays in company valuation due to the Covid-19 effect. Another company, which included the Covid-19 effect in the review of financial statement report, drew attention to the recession that is likely to occur due to the pandemic.

These five companies, which included the Covid-19 effect in their review of financial statement reports, did not include any additional statements regarding whether they benefited from remote audit techniques due to Covid-19 during the audit. Also, in these reports, no explanation that they resorted to additional audit techniques due to the pandemic was encountered.

The restrictions introduced during the Covid-19 pandemic period revealed the importance of the need for a remote audit. It was observed that the remote audit techniques used with Industry 4.0 facilitate the audit activities in this process. We believe that auditors should be more rigorous in remote audit techniques and include more coverage of Covid-19 effects in interim financial reports and review of financial statement reports in order for audit reports to provide more accurate and reliable information to the parties. 


\section{Kaynakça / References}

Accorsi, R. (2011). Business process as a service: Chances for remote auditing. In 2011 IEEE 35th Annual Computer Software and Applications Conference Workshops, 398-403.

Kablan, A. (2018). Endüstri 4.0, "nesnelerin interneti": Akıllı işletmeler ve muhasebe denetimi. Süleyman Demirel Üniversitesi İktisadi ve İdari Bilimler Fakültesi Dergisi, 23(Endüstri 4.0 ve Örgütsel Değişim Özel Sayıs1), 1561-1579.

Karakaya, G. (2020). Covıd-19 gündeminde işletme sürekliliği ve bağımsız denetim ilişkisi. İstanbul Ticaret Üniversitesi Sosyal Bilimler Dergisi, 19(37), 14-29.

Karataş, M. (2020). Covid-19'un denetim çalışmaları üzerine etkileri-muhtemel zorluklar ve dikkat edilmesi gereken hususlar. 17.01.2021 tarihinde http://kovid19.turmob.org.tr/covid-19un-denetim-calismalari-uzerine-etkileri adresinden erişildi.

KGK (2019). Bilgi Notu. 17.01.2021 tarihinde https://www.kgk.gov.tr/Portalv2Uploads/files/Duyurular/v2/TDS/Bilgi_Notu_09_05_2019.pdf adresinden erişildi.

KPMG (2020). Covid 19 gündemi yeni gerçeklikte makro trendler. 17.01.2021 tarihinde https://assets.kpmg/content/dam/kpmg/tr/pdf/2020/07/covid-19-gundemi.pdf adresinden erişildi.

Kurt, G. (2014). Denetim programının yürütülmesi. Ed. S. Kardeş Selimoğlu, Ş.Uzay, Muhasebe Denetimi Ankara: Gazi Kitabevi ISBN: 978-9944-165-74-7

Rezaee, Z., Elam, R., ve Sharbatoghlie, A. (2001). Continuous auditing: the audit of the future". Managerial Auditing Journal, 16(3(, 150-158.

Sınırlı Bağımsız Denetim Standardı (SBDS) 2400 Tarihi Finansal Tabloları Sinırl Bağımsı Denetimi. 30.01.2021 tarihinde https://kgk.gov.tr/Portalv2Uploads/files/Duyurular/v2/SBDS/SBDSyeni11092019/SBDS_2400.pdf adresinden erişildi.

Sınırı Bağımsız Denetim Standardı (SBDS) 2410 Ara Dönem Finansal Bilgilerin, İşletmenin Yıllık Finansal Tablolarının Bă̆ımsız Denetimini Yürüten Denetçi Tarafindan Sınırlı Bă̆ımsız Denetimi. 30.01.2021 tarihinde https://www.kgk.gov.tr/Portalv2Uploads/files/PDF\%20linkleri/standartlar\%20ve\%20ilke\%20kararlar\%C4\%B1/SINIRLI\%20BA\%C4\%9EIMSIZ\%20DENET\%C4\%B0M\%20STANDARTLARI/SBDS 2410 RG.pdf adresinden erişildi.

Sermaye Piyasasında Bağımsız Denetim Standartları Hakkında Tebliğ (Seri: X, No: 22). 30.01.2021 tarihinde https://spk.gov.tr/Sayfa/Dosya/590, adresinden erişildi. 
Teeter, R. A., Alles, M. G., ve Vasarhelyi, M. A. (2010). The remote audit. Journal of Emerging Technologies in Accounting, 7, 1, 73-88.

TÜRMOB (2020) Koronavirüs krizi: Finansal raporlama ve denetim üzerindeki sonuçları. Türkiye Serbest Muhasebeci Mali Müşavirler ve Yeminli Mali Müşavirler Odalar Birliği, 52, 1-1. 25.01.2021 tarihinde https://www.turmob.org.tr/ebulten/TURMOBHaber/52/files/assets/basic-html/page-11.html adresinden erişildi.

Uyar, S. (2015). Denetim standartlarına göre sınırlı bağımsız denetim (Finansal tabloların gözden geçirilmesi. Mali Çözüm Dergisi, 142, 15-39.

https://www.avacert.com/sistem-dokumanlari

https://kgk.gov.tr/Portalv2Uploads/files/Duyurular/v2/BDS/BDSyeni11092019/BDS_520.pdf

https://kgk.gov.tr//ContentAssignmentDetail/4657

\section{Kaynakça Bilgisi / Citation Information}

Karakoç, M. ve Gündüz, M. (2021). Covid 19 sürecinde sınırlı bağımsız denetim ve bıst 100 şirketleri üzerine bir araştırma. OPUS-Uluslararası Toplum Araştırmaları Dergisi, 17(Pandemi Özel Sayısı), 35683592. DOI: $10.26466 /$ opus.895785 